\title{
Associations between adherence to the Danish Food-Based Dietary Guidelines and cardiometabolic risk factors in a Danish adult population: the DIPI study
}

\author{
Johanne L. Arentoft ${ }^{1 *}$, Camilla Hoppe ${ }^{1}$, Elisabeth W. Andersen ${ }^{2}$, Kim Overvad $^{3,4}$ and Inge Tetens ${ }^{5}$ \\ ${ }^{1}$ Division of Diet, Disease Prevention and Toxicology, National Food Institute, Technical University of Denmark, 2800 Kgs. \\ Lyngby, Denmark \\ ${ }^{2}$ Danish Cancer Society, Section for Statistics and Pharmaco-Epidemiology, 2100 Copenhagen, Denmark \\ ${ }^{3}$ Department of Public Health, Section for Epidemiology, Aarbus University, 8000 Aarbus C, Denmark \\ ${ }^{4}$ Department of Cardiology, Aalborg University Hospital, 9000 Aalborg, Denmark \\ ${ }^{5}$ Department of Nutrition, Exercise and Sports, Vitality - Centre for Good Older Lives, University of Copenhagen, 1958 \\ Frederiksberg C, Denmark
}

(Submitted 25 August 2017 - Final revision received 28 November 2017 - Accepted 6 December 2017-First published online 21 January 2018)

\section{Abstract}

Diet is recognised as one modifiable lifestyle factor for ischaemic heart disease (IHD). We aimed at investigating the associations between adherence to the Danish Food-Based Dietary Guidelines (FBDG) indicated by a Dietary Quality Index (DQI) and selected cardiometabolic risk factors in a cross-sectional study with 219 Danish adult participants (59\%women; age 31-65years) with a minimum of one self-rated risk marker of IHD. Information regarding diet was obtained using web-based dietary assessment software and adherence to the Danish FBDG was expressed by a DQI calculated from 5 food and nutrient indicators (whole grain, fish, fruit and vegetables, energy from saturated fat and from added sugar). Background information, blood samples and anthropometrics were collected and blood pressure was measured. Linear regression analyses were used to evaluate the association between DQI and cardiometabolic risk factors. DQI was inversely associated with LDL:HDL ratio and TAG ( -0.089 per unit; $95 \%$ CI $-0 \cdot 177,-0.002$ and $-5 \%$ per unit; $95 \%$ CI -9 , 0 , respectively) and positively associated with HDL-cholesterol (0.047 mmol/1 per unit; $95 \%$ CI 0.007, 0.088). For men, DQI was inversely associated with BMI ( $-3 \%$ per unit; $95 \%$ CI $-5,-1)$, trunk fat $(-1 \%$ per unit; $95 \% \mathrm{CI}-2,-1)$, high-sensitivity C-reactive protein $(-30 \%$ per unit; $95 \% \mathrm{CI}-41,-16 \%), \mathrm{HbA}$ (c) $(-0.09 \%$ per unit; $95 \%$ CI $-0 \cdot 14,-0 \cdot 04)$, insulin $(-13 \%$ per unit; $95 \%$ CI $-19,-7)$ and homoeostatic model assessment-insulin resistance ( $-14 \%$ per unit; $95 \%$ CI $-21,-7)$. In women, DQI was positively associated with systolic blood pressure $(2.6 \mathrm{mmHg}$ per unit; $95 \%$ CI $0 \cdot 6$, 4.6). In conclusion, higher adherence to the current Danish FBDG was associated with a more beneficial cardiometabolic risk profile in a Danish adult population with a minimum of one self-rated risk factor for IHD.

\section{Key words: Dietary patterns: Diet quality: Diet index: Cardiovascular risk factors: Cross-sectional studies}

Ischaemic heart disease (IHD) is one of the major causes of morbidity and mortality worldwide ${ }^{(1,2)}$. Diet is recognised as one of several modifiable lifestyle factors for the prevention of $\operatorname{IHD}^{(1,3,4)}$.

During the past decades, research on diet-disease associations has focused on measurements of overall quality of diets and dietary patterns as opposed to the traditional approach in dietary research with focus on single nutrients and foods ${ }^{(5-8)}$. This change in research focus is justified by the notion that people eat composite diets and meals with nutrients and foods in combination.

Several dietary scores and dietary quality indices have been developed to assess adherence to different healthy food patterns and national Food-Based Dietary Guidelines (FBDG $)^{(6,9,10)}$. Some of the most commonly used are The Mediterranean diet score indicating compliance with the traditional dietary pattern followed by Mediterranean populations, and the American Healthy Eating Index (HEI), which assesses adherence with the Dietary Guidelines for Americans ${ }^{(11)}$. Both observational and intervention studies have shown a protective effect on the development and mortality of CVD with a higher compliance to the Mediterranean diet and the Dietary Guidelines for Americans ${ }^{(12-16)}$.

The Mediterranean diet score and the American HEI are considered most suitable for the Mediterranean countries and the Americans and for countries with similar food cultures,

Abbreviations: BP, blood pressure; DQI, Dietary Quality Index; DQS, Dietary Quality Score; E\%, energy contribution; FBDG, Food-Based Dietary Guidelines; HEI, Healthy Eating Index; HOMA-IR, homoeostatic model of insulin resistance; hsCRP, high-sensitivity C-reactive protein; IHD, ischaemic heart disease; OR, over-reporters; UR, under-reporters; WC, waist circumference.

* Corresponding author: J. L. Arentoft, email joloa@food.dtu.dk 
respectively. In the Nordic countries, including Denmark, a different food culture exists with a dietary pattern relatively abundant in certain fruit and vegetables (especially berries, cabbages, root vegetables and legumes), potatoes, whole-grain cereals, dairy and meat products ${ }^{(17)}$. The Danish food culture and food preferences were included as an integrated part in the development of the current Danish FBDG when translating the scientific evidence regarding the association between diet and risk of diseases into quantified $\mathrm{FBDG}^{(18)}$.

In Denmark, two dietary quality indices have been developed to measure adherence to the Danish FBDG from $2005^{(19,20)}$. One is the Dietary Quality Score (DQS), which is based on a fortyeight-item FFQ, and uses a three-point scoring system for each of four food groups: fish, fruit, vegetables and fats. The DQS has been found to be inversely associated with serum lipids, homocysteine and absolute risk of IHD in men and women aged 30-60 years ${ }^{(19)}$. The other, the Diet Quality Index (DQI), is based on dietary data from a $7-\mathrm{d}$ pre-coded food diary, and uses a sum of six scores of food and nutrients based on the 2005 FBDG relating to dietary intake ${ }^{(20,21)}$. In continuation of the update of the Danish FBDG in 2013, an updated version of the DQI was applied to reflect the changes in the $\mathrm{FBDG}^{(18,22)}$. The updated DQI is based on five food and nutrient indicators, including whole grain, fish, fruit and vegetables and energy \% from saturated fat and from added sugar ${ }^{(20,22)}$

The objective of this study was to investigate associations between adherence to the current Danish FBDG assessed by a DQI and selected cardiometabolic risk factors in a Danish adult population with a minimum of one self-rated risk factor of IHD.

\section{Methods}

\section{Study design}

The study was based on baseline data from the study Diet and Prevention of Ischemic Heart Disease - a Translational Approach (DIPI) (www.DIPI.dk), which included a 6-month randomised, single-blinded parallel, dietary intervention study in a real-life setting, with a 6-month follow-up. The study was designed to assess the effects of dietary substitution guidelines specifically aimed at the prevention of IHD on dietary intake and IHD risk factors in the general adult Danish population. This paper reports on the baseline cross-sectional data.

This study was conducted according to the guidelines laid down in the Declaration of Helsinki and was approved by The Capital Region of Denmark Ethics Committee (Journal no. H-12013-110) and by the Danish Data Protection Agency (Journal no. 2013-54-0571). Written informed consent was obtained from all study participants, and they received a small remuneration of about 34 GBP for their participation in the study. The study was registered at ClinicalTrials.gov (registry name 'DIPI', ID no. NCT02062424).

\section{Study participants}

Potential participants were identified using a unique personal identification number assigned to all Danish citizens in the Civil Registration System ${ }^{(23)}$. In total, 5000 men and women born in 1949-1984 and living in a defined area of the greater
Copenhagen were invited by letter to participate in the study. The number of invited participants was based on previous experience of a low response rate when recruiting participants for long-term interventions. Overall, 334 responded on the invitation and were thus screened from a self-administered questionnaire including questions on the inclusion and exclusion criteria. The potential participants were asked in the questionnaire to measure and report their height in metres, weight in $\mathrm{kg}$, their waist circumference (WC) $2 \mathrm{~cm}$ above their belly button and whether or not they were physically active for more than $15 \mathrm{~min} /$ week. Furthermore, the self-administered questionnaire included questions on the exclusion criteria; see below. After screening, the eligible participants were invited to an information meeting, which included an introduction to the web-based dietary assessment software. Of the eligible participants who participated in the information meeting, $100 \%$ agreed to participate and provided informed consent.

The inclusion criteria were age between 30 and 65 years, and a minimum of one self-rated risk factor of IHD - that is overweight or obesity (BMI $\geq 25$ ) - WC $\geq 80 \mathrm{~cm}$ for women and $\geq 94 \mathrm{~cm}$ for men, and/or physical inactivity defined as being moderately physically active in leisure time for $15 \mathrm{~min}$ or less per week.

The exclusion criteria were current smoking, pregnancy or plans to become pregnant within the next 12 months, breastfeeding, history of CVD, type 2 diabetes, chronic disease/ disorders that could affect the results of the study (the chronic diseases that the subjects reported were evaluated by the clinical physician in charge), drug abuse within the past 12 months, regular alcohol consumption $>21$ units/week for men or $>14$ units/week for women, allergies or intolerance of the food groups included in the dietary guidelines, consumption of dietary supplements with high doses of nutrients that could have a potential effect on IHD risk factors (e.g. fish oils) and/or no access to a computer and internet.

\section{Measures}

Dietary intake and calculation of diet quality index. The study participants recorded their dietary intake using a web-based dietary assessment software for 7 consecutive days ${ }^{(24)}$. The webbased dietary assessment software was originally developed and validated for children aged 8-11 years and slightly customised to fit the adult study population of the DIPI study ${ }^{(24,25)}$. At least $4 \mathrm{~d}$ of food reporting had to be completed by the study participant for inclusion of the study participants in the analysis ${ }^{(21)}$

The dietary assessment software was structured according to a typical Danish meal pattern covering breakfast, lunch, dinner and three in-between meals. The participants could estimate the amount consumed by selecting the closest portion size among four different digital images in eighty photograph series. Internal checks for frequently forgotten foods (spreads, sugar, sauces, dressings, snacks, candy and beverages) were included. Furthermore, the participants reported the intake of nutritional supplements and whether a day represented usual or unusual intake, including reasons for unusual intakes such as illness. If a participant failed to report for a day, the participant was reminded by an email the next day ${ }^{(24)}$. 
Intakes of food items, energy and nutrients were calculated for each study participant as an average of $7 \mathrm{~d}$ using the software system General Intake Estimation System (GIES) version 1.000.i6 (National Food Institute, Technical University of Denmark) and the Danish Food Composition Databank version 7.0 (National Food Institute Technical University of Denmark, 2009).

Adherence to the Danish FBDG was evaluated based on a DQI published earlier and updated to the current Danish FBDG ${ }^{(20,22)}$, including intake of whole grain ( $\min 75 \mathrm{~g} / 10 \mathrm{MJ}$ per $\mathrm{d}$ ), intake of fish (min $350 \mathrm{~g} / 10 \mathrm{MJ}$ per week), intake of fruit and vegetables (min $600 \mathrm{~g} / 10 \mathrm{MJ}$ per $\mathrm{d}$ ), energy from saturated fat $(\max 10 \mathrm{E} \%)$ and energy from added sugar $(\max 10 \mathrm{E} \%)$. The DQI was based on intake adjusted to $10 \mathrm{MJ}$, as this is the unit for the $\mathrm{FBDG}^{(18)}$

A DQI for each study participant was calculated - adapted from $^{(20)}$ - as the ratio of the actual intake and the recommend intake of each of the five guidelines included in the index. For example, if a study participant had an intake of $60 \mathrm{~g} / 10 \mathrm{MJ}$ perd whole grain, the score was $60 / 75=0 \cdot 8$. For the included guidelines with an upper limit of a recommended intake, the DQI was calculated as 1 -((intake-recommended)/recommended), and thus for a study participant with an intake of $13 \%$ energy from added sugar the DQI was calculated as $1-((13-10) / 10)=0 \cdot 7$.

In contrast to the original DQI, we did not have a maximum score in individuals with an intake exceeding the cut-off values $^{(20)}$. The total score was calculated as the sum of the five scores, a higher score meaning a higher degree of compliance with the FBDG.

Under- and over-reporters. Under- and over-reported energy intake (EI) was defined as a ratio of reported mean EI:BMR and classified by cut-offs suggested by Black ${ }^{(26,27)}$. Under-reporters (UR) were defined as EI:BMR $\leq 1.05$ and over-reporters (OR) were defined as EI:BMR $\geq 2 \cdot 28$, using a physical activity level of 1.55 (data not shown)

\section{Assessment of cardiometabolic risk factors}

Blood samples. Fasting blood samples from venepuncture were analysed for concentrations of TAG, total cholesterol, HDL-cholesterol, high-sensitivity C-reactive protein (hsCRP), glucose, $\mathrm{HbA}_{1 \mathrm{c}}$ and insulin. The blood samples were collected and handled according to the hospital routines. TAG, total cholesterol, HDL-cholesterol and glucose were measured in plasma by Reflection Spectroscopy at $540 \mathrm{~nm}$ and hsCRP was measured in plasma by Reflection Spectroscopy at $660 \mathrm{~nm}$ (Apparatus Vitros 5.1 FS; Ortho-Clinical Diagnostics). $\mathrm{HbA}_{1 \mathrm{c}}$ was measured in plasma with HPLC (D-100; Bio-Rad). Fasting plasma insulin was measured using the sandwich ELISA analysis principle (ADVIA Centaur XP; Siemens). VLDL-cholesterol was calculated from TAG, using the equation plasma VLDLcholesterol $=$ plasma $\mathrm{TAG} \times 0.45$, and LDL-cholesterol was calculated using the Friedewald equation ${ }^{(28)}$.

The homoeostatic model assessment (HOMA) was used to estimate insulin resistance (HOMA-IR). HOMA-IR was calculated using the formula HOMA-IR $=($ glucose $(\mathrm{nmol} / \mathrm{l}) \times$ insulin $(\mathrm{mU} / \mathrm{ml}) / 22 \cdot 5)$, using fasting values ${ }^{(29)}$.
Anthropometric measurements (height, weight and waist circumference). Height was measured to the nearest $0.5 \mathrm{~cm}$, on a wall-mounted stadiometer (SECA). Body weight was measured in $\mathrm{kg}$ and trunk fat was registered on a fat analysis weight (Tanita BC 418 MA). The subjects had to be fasting. Waist and hip circumference was measured twice, with an anthropometric tape (SECA 201), and the average was reported.

BMI was defined as weight in kg divided by squared height in metres $\left(\mathrm{kg} / \mathrm{m}^{2}\right)$.

Blood pressure and heart rate. Seated blood pressure (BP) and heart rate (HR) were measured in duplicate after 5 min of rest in the subjects' left arm, using an electric sphygmomanometer according to standardised procedures. The subjects had to empty their bladder before the measurement and were not allowed to converse during the measurement, nor have their legs crossed. If the diastolic BP differed more than $5 \mathrm{mmHg}$, further measurements were done, until at least in two measurements the diastolic BP differed $\leq 5 \mathrm{mmHg}$. The average value of the two BP and HR measurements was calculated.

Assessment of background questionnaires. Lifestyle questionnaires were used to obtain information about the participant's education level (primary school/high school, associate degree, under-graduate, graduate) and the level of physical activity at leisure time (extremely active, moderately active, sedentary or inactive). The question about the level of physical activity was based on one question about the study participants' physical activity during leisure time in the past 6 month and was based upon the Danish National Health Profile ${ }^{(30)}$.

\section{Statistical analysis}

For a parallel design, statistical power calculations based on evidence from previous similar studies ${ }^{(31-33)}$ were used to estimate that sixty-two subjects in each intervention arm were sufficient to detect a difference of $0.25 \mathrm{mmol} / \mathrm{l} \mathrm{LDL}$-cholesterol (sD 0.49$)(\alpha=0 \cdot 05, \beta=0 \cdot 8)$. To allow for a drop-out of $20 \%$, the number of participants was set to a total of 225 . Self-rated weight (kg), WC and BMI from the screening self-administered questionnaire were compared with weight, WC and BMI measured at baseline by a paired $t$ test. Baseline characteristics and dietary intake of the study participants were summarised for men and women using medians and $80 \%$ central range for continuous variables and proportions for categorical variables.

Linear regression analyses were used to evaluate the association between DQI and cardiometabolic risk factors. Three models were applied; a simple model adjusted for sex and age $(<50$ or $\geq 50$ ) (model $1 \mathrm{a})$, a multivariate model further adjusted for education (primary school/high school, associate degree, under-graduate or graduate) and physical activity at leisure time (extremely active, moderately active, sedentary or inactive) (model 1b), and a final multivariate model adjusted as model 1b plus BMI (model 2). Furthermore, sensitivity analysis excluding UR and OR was made to investigate the impact of UR and OR on the associations between DQI and cardiometabolic risk factors. 
All the models were tested for statistically significant interactions between DQI and sex and DQI and age. These interactions were tested to investigate whether the associations were different for men and women and for participants $<50$ years of age or 50 years of age or above. If an interaction was significant, the DQI estimates for men and women and DQI estimates by age were given. To check the model assumptions, the standardised residuals of the final models were examined for normality, variance homogeneity and linearity. BMI, waist:hip-ratio, hsCRP, VLDL-cholesterol, TAG, glucose, insulin and HOMA-IR were all logarithm10 transformed to normalise the distribution and to improve variance homogeneity. For the abovementioned variables, which were log-transformed, the estimates and 95\% CI are presented as percent difference.

The statistical analyses were carried out using RStudio (version 0.99.441 - (C) 2009-2015; RStudio, Inc.). Statistical significance was established at $P<0.05$.

\section{Results}

\section{Baseline characteristics of study participants}

A total of 222 participants met the inclusion and exclusion criteria and were enrolled into the study, which was $67 \%$ of the initially screened potential study participants. Significant differences $(P<0.05)$ in weight and WC were found between self-reported and measured at baseline. The participants' self-reported weight and WC were higher than the measured weight and WC at baseline. However, no difference in BMI was found. In all, 17\% of the women and $7 \%$ of the men did not meet the inclusion criteria when measured at baseline (data not shown). For three participants, a full baseline examination was missing, and they were therefore excluded. Of the remaining 219 study participants, those who were taking cholesterol-lowering ( $n$ 5) and/or BP-lowering ( $n$ 3) medications were excluded from the statistical analysis of the association between DQI and lipid biomarkers and DQI and BP, respectively. In addition, biochemical analysis of hsCRP was not possible in fifteen study participants; therefore, for the statistical analysis of the association between DQI and hsCRP, the number of participants was 204. Furthermore, it was not possible to get sufficient blood from one of the study participants for the biochemical analysis of the glycaemic biomarkers, and thus for the statistical analysis of the association between DQI and glycaemic biomarkers ( $n$ 218).

Baseline characteristics of the 219 study participants included in the statistical analysis are presented in Table 1. Of the 219 study participants, ninety were men and 129 were women. The median age of the study participants was 51 years (10th-90th percentile (p10-p90) 37-61).

\section{Diet quality index, total energy intake and dietary composition}

For the whole study population the median DQI was 4.5 (p10-p90 3.0-6.5). The median DQI score was higher for women than for men. Furthermore, the median individual DQI score for added sugar was higher than the median DQI scores for whole grain, fish, fruit and vegetables and saturated fat.
Median total EI for men was 10.1 MJ (p10-p90 7.2-13.7) and for women it was $7 \cdot 8 \mathrm{MJ}$ (p10-p90 5.2-10.5) (Table 2). Medians (p10-p90) of the Diet Quality Index score (DQI), energy $(\mathrm{MJ} / \mathrm{d})$, diet composition $(\mathrm{g} / 10 \mathrm{MJ}$ per $\mathrm{d})$ and energy contribution $(\mathrm{E} \%)$ of macronutrients and dietary fibre $(\mathrm{g} / \mathrm{MJ})$ of the study population divided in tertiles of the DQI are presented in the online Supplementary Table S1.

\section{Association between Dietary Quality Index and cardiometabolic risk factors}

Table 3 summarises the associations between DQI and cardiometabolic risk factors in the study population. In the following section, only results from model $1 \mathrm{~b}$ will be presented.

We found an inverse association between DQI and the lipid risk factors - LDL:HDL ratio and TAG (-0.089 per unit DQI; $95 \%$ CI $-0 \cdot 177,-0.002$ and $-5 \%$ per unit DQI; $95 \%$ CI $-9,0$, respectively) - and a positive association between DQI and HDLcholesterol (0.047 mmol/1 per unit DQI; $95 \%$ CI 0.007, 0.088). For men only, we found an inverse association between DQI and BMI ( $-3 \%$ per unit DQI; $95 \% \mathrm{CI}-5,-1)$, trunk fat $(-1 \%$ per unit DQI; $95 \%$ CI $-2,-1)$, hsCRP ( $-30 \%$ per unit DQI; $95 \% \mathrm{CI}-41,-16)$ and the glycaemic risk factors, $\mathrm{HbA}_{1 \mathrm{c}}(-0.09 \%$ per unit $\mathrm{DQI} ; 95 \%$ CI $-0 \cdot 14,-0 \cdot 04)$, insulin ( $-13 \%$ per unit DQI; 95\% CI $-19,-7)$ and HOMA-IR $(-14 \%$ per unit DQI; $95 \%$ CI $-21,-7)$. Furthermore, we found a positive association between DQI and systolic BP in women $(2.6 \mathrm{mmHg}$ per unit DQI; $95 \%$ CI 0.6, 4.6).

\section{Under- and over-reporters}

Overall, $21 \%$ of the participants were classified as UR and 1\% as OR. Of those classified as UR, $89 \%$ were overweight or obese, $46 \%$ of the UR were men and all of the OR were men.

The associations between DQI and most of the variables included were the same whether UR and OR were included in the analysis or not. However, for the metabolic markers BMI, trunk fat, systolic BP and hsCRP, the interaction between DQI and sex was no longer significant when excluding UR and OR. Except for BMI, the association between DQI and these metabolic markers was now significant for the whole study population (trunk fat: $-1 \%$ per unit DQI; $95 \% \mathrm{CI}-2,-0 \cdot 4$, systolic BP: $1.7 \mathrm{mmHg}$ per unit DQI; 95\% CI 0.08, 3.36, and hsCRP $-23 \%$ per unit DQI; $95 \%$ CI $-32,-12$ ). Furthermore, the metabolic markers waist:hip-ratio changed from being nonsignificant to significant ( -1 per unit DQI; 95\% CI $-2,0)$. In addition, the observed positive association between DQI and HDL-cholesterol was only significant in study participants aged 50 years or above when excluding UR and OR from the analysis (0.09 mmol/L per unit DQI; 95\% CI 0.034, 0.045).

\section{Discussion}

In the present study, a higher adherence to the current Danish FBDG, assessed by a DQI, was associated with a more beneficial cardiometabolic risk profile in a Danish adult population with a minimum of one self-rated risk factor for IHD. The main findings were the inverse associations between the DQI and the lipid risk factors: LDL:HDL ratio and TAG and the positive 
Table 1. Baseline characteristics of the study participants divided by sex (Medians and 10th-90th percentiles (p10-p90); percentages and numbers)

\begin{tabular}{|c|c|c|c|c|c|c|}
\hline \multirow[b]{2}{*}{ Participant characteristics } & \multicolumn{2}{|c|}{ All $(n 219)$} & \multicolumn{2}{|c|}{ Men $(n 90)$} & \multicolumn{2}{|c|}{ Women ( $n$ 129) } \\
\hline & Median & p10-p90 & Median & p10-p90 & Median & p10-p90 \\
\hline Age (years) & $51 \cdot 0$ & $37-61$ & 50.5 & $36-61$ & $51 \cdot 0$ & $37-61$ \\
\hline \multicolumn{7}{|l|}{ Metabolic markers } \\
\hline Weight $(\mathrm{kg})$ & 82.6 & $65 \cdot 3-103 \cdot 6$ & 88.4 & $79-117.5$ & 74.6 & $62 \cdot 3-92 \cdot 8$ \\
\hline $\operatorname{BMI}\left(\mathrm{kg} / \mathrm{m}^{2}\right)^{\star}$ & $26 \cdot 7$ & $22.9-33.6$ & $27 \cdot 0$ & $23.9-33.9$ & $26 \cdot 3$ & $22.6-32.9$ \\
\hline \multicolumn{7}{|l|}{ Weight status* } \\
\hline \multicolumn{7}{|l|}{ Normal weight } \\
\hline$\%$ & \multicolumn{2}{|c|}{27} & \multicolumn{2}{|c|}{16} & \multicolumn{2}{|c|}{36} \\
\hline$n$ & \multicolumn{2}{|c|}{60} & \multicolumn{2}{|c|}{14} & \multicolumn{2}{|c|}{46} \\
\hline \multirow{2}{*}{\multicolumn{7}{|c|}{ Overweight }} \\
\hline$\%$ & \multicolumn{2}{|c|}{53} & \multicolumn{2}{|c|}{66} & & 43 \\
\hline$n$ & \multicolumn{2}{|c|}{116} & \multicolumn{2}{|c|}{60} & \multicolumn{2}{|c|}{56} \\
\hline \multicolumn{7}{|l|}{ Obese } \\
\hline$\%$ & \multirow{2}{*}{\multicolumn{2}{|c|}{$\begin{array}{l}20 \\
43\end{array}$}} & \multicolumn{2}{|c|}{18} & & \\
\hline$n$ & & & & & & \\
\hline Waist circumference $(\mathrm{cm})$ & 92.4 & $79 \cdot 8-105 \cdot 2$ & 97.4 & $90 \cdot 8-118 \cdot 3$ & 87.0 & $76 \cdot 8-99.5$ \\
\hline Hip circumference $(\mathrm{cm})$ & $107 \cdot 1$ & $99 \cdot 4-120.0$ & $106 \cdot 7$ & $102 \cdot 3-118 \cdot 7$ & $108 \cdot 2$ & $98 \cdot 9-120 \cdot 4$ \\
\hline Systolic BP $(\mathrm{mmHg}) \dagger$ & 130 & $110-154$ & 135 & $119-164$ & 125 & $108-149$ \\
\hline Diastolic BP $(\mathrm{mmHg}) \dagger$ & 80 & $69-94$ & 82 & $72-98$ & 78 & 68-92 \\
\hline hsCRP (mg/l)‡ & 1.4 & $0.2-6 \cdot 3$ & 1.0 & $0.2-5 \cdot 4$ & 1.9 & $0.2-8 \cdot 3$ \\
\hline Lipid biomarkers§ & & & & & & \\
\hline Total cholesterol $(\mathrm{mmol} / \mathrm{l})$ & $5 \cdot 3$ & $4 \cdot 1-6 \cdot 8$ & 5.5 & $4.4-6.9$ & $5 \cdot 2$ & $4.0-4.5$ \\
\hline LDL-cholesterol (mmol/l/) & $3 \cdot 2$ & $2 \cdot 2-4.5$ & 3.5 & $2.5-4.7$ & $3 \cdot 1$ & $2 \cdot 1-4.5$ \\
\hline HDL-cholesterol (mmol/l) & 1.4 & $1.0-3.9$ & $1 \cdot 2$ & $0.9-1.9$ & 1.6 & $1 \cdot 1-2 \cdot 3$ \\
\hline LDL:HDL ratio & $2 \cdot 3$ & $4 \cdot 1-6 \cdot 8$ & $2 \cdot 8$ & $1.7-4.3$ & $2 \cdot 0$ & $1 \cdot 2-3 \cdot 0$ \\
\hline VLDL-cholesterol $(\mathrm{mmol} / \mathrm{l})$ & 0.5 & $0.3-1.0$ & 0.6 & $0.3-1 \cdot 2$ & 0.4 & $0.3-0.8$ \\
\hline TAG $(\mathrm{mmol} / \mathrm{l})$ & $1 \cdot 1$ & $0.6-2.3$ & 1.3 & $0.7-2.6$ & 0.9 & $0 \cdot 6-1 \cdot 8$ \\
\hline Glycaemic biomarkers\| & & & & & & \\
\hline Glucose $(\mathrm{mmol} / \mathrm{l})$ & 5.5 & $5 \cdot 0-6 \cdot 3$ & $5 \cdot 6$ & $5 \cdot 1-6 \cdot 4$ & 5.4 & $4.9-6 \cdot 1$ \\
\hline $\mathrm{HbA}_{1 \mathrm{c}}(\%)$ & 5.0 & $4.5-5 \cdot 5$ & 5.0 & $4 \cdot 6-5.5$ & 5.0 & $4.5-5.5$ \\
\hline Insulin (pmol/l) & 58 & $30-100$ & 59 & $31-127$ & 58 & $30-94$ \\
\hline HOMA-IR & $2 \cdot 0$ & $1.0-3.8$ & $2 \cdot 2$ & $1.0-4.6$ & $2 \cdot 0$ & $1.0-3.6$ \\
\hline Educational level & & & & & & \\
\hline Primary school or high sch & & & & & & \\
\hline$\%$ & & & & & & \\
\hline$n$ & & & & & & \\
\hline Associate degree & & & & & & \\
\hline$\%$ & & & & & & \\
\hline$n$ & & & & & & \\
\hline Under-graduate school & & & & & & \\
\hline$\%$ & & & & & & \\
\hline$n$ & & & & & & \\
\hline Graduate school & & & & & & \\
\hline$\%$ & & & & & & \\
\hline$n$ & & & & & & \\
\hline
\end{tabular}

BP, blood pressure; hsCRP, high-sensitivity C-reactive protein; HOMA-IR, homoeostatic model of insulin resistance.

${ }^{*} \mathrm{BMl}$ is calculated as weight in $\mathrm{kg}$ divided by the square of height in $\mathrm{m}\left(\mathrm{kg} / \mathrm{m}^{2}\right) .18 \cdot 5-25 \mathrm{~kg} / \mathrm{m}^{2}$ : normal weight, $25-30 \mathrm{~kg} / \mathrm{m}^{2}$ : overweight, $>30 \mathrm{~kg} / \mathrm{m}^{2}$ : obese.

$\dagger$ All; 216, men; eighty-nine, women; 127, after exclusion of those using BP-lowering medication.

$\ddagger$ All; 204, men; eighty-seven, women; 117, due to lack of hsCRP in biochemical analyses.

§ All; 214, men; eighty-five, after exclusion of those using cholesterol-lowering medication.

II All; 218, women; 128, as it was not possible to draw enough blood to the glycaemic biomarker analysis from one of the female study participants.

association with HDL-cholesterol. For the male study participants, an inverse association between DQI and BMI, trunk fat, hsCRP and the glycaemic risk factors, $\mathrm{HbA}_{1 \mathrm{c}}$, insulin and HOMA-IR was observed. Furthermore, we found a positive association between DQI and systolic BP in women.

When we controlled for the effect of BMI on cardiometabolic risk factors, the associations between DQI and trunk fat, LDL: HDL ratio and TAG were attenuated and no longer statistically significant, suggesting that BMI could be an important factor in CVD prevention. Of that notion it is important to further investigate whether the association of higher adherence to the
Danish FBDG and a more beneficial cardiometabolic risk profile is due to the effect of the Danish FBDG, expressed by DQI, on BMI and body composition, including trunk fat, or whether the association is independent. We only found an inverse significant association between DQI and BMI in men, suggesting that a higher DQI score (indication of a higher adherence to the Danish FBDG) is only associated with a lower BMI in men and not women. The fact that DQI and BMI was only associated in men and not in women could be explained by the higher number of normal-weight women than men, and the higher number of overweight men than women. Moreover, 
Table 2. Overall Diet Quality Index (DQI) score and DQI scores for individual components, energy (MJ/d), diet composition ( $\mathrm{g} / 10 \mathrm{MJ}$ per d) and energy contribution (E\%) of macronutrients and dietary fibre (g/MJ) of the study participants

(Medians and 10th-90th percentiles (p10-p90))

\begin{tabular}{|c|c|c|c|c|c|c|c|c|c|}
\hline \multirow[b]{2}{*}{ Participants } & \multirow{2}{*}{$\begin{array}{l}\text { Guidelines and } \\
\text { recommendations* }\end{array}$} & \multicolumn{2}{|c|}{ All (219) } & \multicolumn{2}{|c|}{ Men ( $n$ 90) } & \multicolumn{2}{|c|}{ Women ( $n$ 129) } & \multicolumn{2}{|c|}{ DQI score } \\
\hline & & Median & p10-p90 & Median & p10-p90 & Median & p10-p90 & Median & p10-p90 \\
\hline Overall DQI & & 4.5 & $3.0-6 \cdot 5$ & $4 \cdot 2$ & $2 \cdot 7-6 \cdot 2$ & 4.6 & $3.0-6 \cdot 6$ & & \\
\hline Energy $(\mathrm{MJ} / \mathrm{d})$ & & 8.6 & $5 \cdot 8-12 \cdot 4$ & $10 \cdot 1$ & $7 \cdot 2-13 \cdot 7$ & 7.8 & $5 \cdot 2-10 \cdot 5$ & & \\
\hline \multicolumn{10}{|l|}{ Diet composition $(\mathrm{g} / 10 \mathrm{MJ} / \mathrm{d})$} \\
\hline Bread and cereals* & & 218 & $141-301$ & 215 & $149-291$ & 220 & $136-307$ & & \\
\hline Whole grains & $75 \mathrm{~g} / \mathrm{d}$ & 61 & $31-111$ & 56 & $30-117$ & 66 & $34-108$ & 0.8 & $0.4-1.5$ \\
\hline Meat and meat products & $<70 \mathrm{~g} / \mathrm{d}$ & 139 & $59-249$ & 166 & $85-282$ & 124 & $45-224$ & & \\
\hline Fish and fish productst & $50 \mathrm{~g} / \mathrm{d}$ & 46 & $5-111$ & 41 & 5-109 & 48 & $5-125$ & 0.9 & $0 \cdot 1-2 \cdot 2$ \\
\hline Poultry and poultry productsł & & 32 & 0-102 & 31 & $0-103$ & 32 & $0-99$ & & \\
\hline Fruit and vegetables & $600 \mathrm{~g} / \mathrm{d} \S$ & 388 & $177-690$ & 324 & $144-508$ & 452 & $243-749$ & 0.6 & $0.3-1 \cdot 2$ \\
\hline Fruit and fruit products & & 143 & $43-331$ & 100 & $23-245$ & 180 & $64-362$ & & \\
\hline Vegetables and vegetable products & & 220 & $110-425$ & 194 & $84-348$ & 237 & $132-469$ & & \\
\hline Vegetables, coarsell & & 97 & $29-208$ & 83 & 23-191 & 104 & $39-215$ & & \\
\hline Vegetables, finell & & 114 & $49-228$ & 95 & $37-167$ & 122 & $68-255$ & & \\
\hline Potatoes and potato products & & 57 & $7-138$ & 73 & $15-152$ & 47 & $2-126$ & & \\
\hline Milk and milk products & & 243 & $68-513$ & 213 & $68-484$ & 272 & $70-531$ & & \\
\hline Cheese and cheese products & Choose low fat & 45 & $11-129$ & 36 & $5-97$ & 50 & $16-156$ & & \\
\hline Edible fats & & 31 & $18-46$ & 30 & $16-48$ & 31 & $18-45$ & & \\
\hline Sugar and candy & Reduce intake & 35 & $10-77$ & 31 & $10-76$ & 38 & $14-77$ & & \\
\hline \multicolumn{10}{|l|}{ Energy distribution } \\
\hline Protein $(E \%)$ & $10-20$ & 17 & $14-22$ & 17 & $14-21$ & 17 & $14-22$ & & \\
\hline Fat $(\mathrm{E} \%)$ & $25-40$ & 35 & $29-42$ & 35 & $28-40$ & 36 & $29-43$ & & \\
\hline SFA (E\%) & $<10$ & 13 & $11-17$ & 13 & $10-17$ & 13 & $11-16$ & 0.7 & $0.4-0.9$ \\
\hline MUFA (E\%) & $10-20$ & 13 & $10-17$ & 13 & $10-16$ & 14 & $11-18$ & & \\
\hline PUFA (E\%) & $5-10$ & 5 & $4-7$ & 5 & $4-6$ & 5 & $4-7$ & & \\
\hline Carbohydrate (E\%) & $45-60$ & 44 & $35-53$ & 43 & $34-53$ & 45 & $35-53$ & & \\
\hline Added sugar (E\%) & $<10$ & 7 & $2-13$ & 7 & $2-15$ & 7 & $3-13$ & 1.3 & $0.7-1.8$ \\
\hline Dietary fibre $(\mathrm{g} / \mathrm{MJ})$ & $>3 \mathrm{~g} / \mathrm{MJ}$ & 2 & $2-3$ & 2 & $2-3$ & 3 & $2-4$ & & \\
\hline Alcohol $(\mathrm{E} \%)$ & $<5$ & 5 & $1-14$ & 7 & $1-16$ & 4 & $0-10$ & & \\
\hline
\end{tabular}

* Guidelines and recommendations according to the official Danish Food-Based Dietary Guidelines ${ }^{(18)}$ and the Nordic Nutrition Recommendations, 2012(8).

† All; $n$ 201, men; eighty-three, women; 118 after exclusion of those who did not eat fish.

\&at 6 a day - equivalent to about $600 \mathrm{~g}$ of vegetables and fruit. At least half should be vegetables.

II Vegetables are classified from type of food groups (e.g. all types of cabbage, root vegetables and onions are classified as coarse vegetables and all vegetables with a high water content like tomatoes and salad are classified as fine

vegetables).
Ill; 194, men; eighty-one, women; 113 after exclusion of those who did not drink alcohol. 
Table 3. Linear regression of the associations between adherence to the Danish Food-Based Dietary Guidelines (FBDG) assessed by a diet quality index $(\mathrm{DQI})$ and cardiometabolic risk factors in a Danish adult population with minimum one self-rated risk factor for Ischaemic heart disease ( $\beta$-Coefficients per unit DQI and $95 \%$ confidence intervals)

\begin{tabular}{|c|c|c|c|c|c|c|}
\hline & \multicolumn{2}{|c|}{ Model 1a† } & \multicolumn{2}{|c|}{ Model 1b $\ddagger$} & \multicolumn{2}{|c|}{ Model $2 \S$} \\
\hline & $\beta$ & $95 \% \mathrm{Cl}$ & $\beta$ & $95 \% \mathrm{Cl}$ & $\beta$ & $95 \% \mathrm{Cl}$ \\
\hline \multicolumn{7}{|l|}{ Metabolic markers ( $n$ 219) } \\
\hline $\mathrm{BMI}\left(\mathrm{kg} / \mathrm{m}^{2}\right)(\%)$ & 0 & $-2,1$ & 0 & $-1,2$ & & \\
\hline Men & $-3^{\star}$ & $-5,1$ & $-3^{\star \star}$ & $-5,-1$ & & \\
\hline Women & 0 & $-2,1$ & 0 & $-1,2$ & & \\
\hline Waist:hip-ratio (\%) & -1 & $-1,0$ & -1 & $-1,0$ & -1 & $-2,0$ \\
\hline Trunk fat $(\%)$ & $-1^{*}$ & $-1,0$ & 0 & $-1,1$ & 0 & $-1,0$ \\
\hline Men & & & $-1^{\star \star \star}$ & $-2,-1$ & & \\
\hline Women & & & 0.02 & $-0.69,0.73$ & & \\
\hline Systolic BP (mmHg)\| & 0.81 & $-0 \cdot 7,2 \cdot 3$ & $1 \cdot 15$ & $-0.36,2.67$ & $1.59^{\star}$ & $0.11,3.07$ \\
\hline Men & & & -0.68 & $-3.04,1.68$ & & \\
\hline Women & & & $2 \cdot 6^{\star}$ & $0.63,4.58$ & & \\
\hline Diastolic BP $(\mathrm{mmHg}) \|$ & -0.24 & $-1 \cdot 19,0.71$ & 0.92 & $-0.3,2.13$ & 0.3 & $-0.56,1.17$ \\
\hline Men & & & -1.33 & $-2 \cdot 78,0 \cdot 12$ & & \\
\hline Women & & & 0.92 & $-0 \cdot 3,2 \cdot 13$ & & \\
\hline hsCRP (mg/l) (\%)ף & $-16^{\star \star}$ & $-25,-6$ & $-16^{\star \star}$ & $-25,-6$ & $-12^{*}$ & $-21,-2$ \\
\hline Men & $-29^{\star \star *}$ & $-40,-15$ & $-30^{\star \star \star}$ & $-41,-16$ & & \\
\hline Women & -7 & $-19,7$ & -5 & $-18,9$ & & \\
\hline \multicolumn{7}{|l|}{ Lipid biomarkers (n 214) } \\
\hline Total cholesterol (mmol/l) & 0.005 & $-0.089,0.099$ & -0.009 & $-0.104,0.087$ & -0.006 & $-0.101,0.090$ \\
\hline LDL-cholesterol (mmol/l) & -0.017 & $-0.098,0.065$ & -0.027 & $-0.110,0.055$ & -0.024 & $-0.106,0.059$ \\
\hline HDL-cholesterol (mmol/l) & $-0.052^{*}$ & $0.012,0.092$ & $0.047^{\star}$ & $0.007,0.088$ & -0.009 & $-0.071,0.052$ \\
\hline$<50$ years & & & & & -0.009 & $-0.071,0.052$ \\
\hline$>50$ years & & & & & $0.071^{\star *}$ & $0.021,0.120$ \\
\hline LDL:HDL-ratio & $-0.088^{\star}$ & $-0.175,-0.002$ & $-0.089^{*}$ & $-0.177,-0.002$ & -0.074 & $-0.158,0.010$ \\
\hline VLDL-cholesterol (mmol/l) (\%) & $-5^{*}$ & $-9,-1$ & -5 & $-9,0$ & -4 & $-8,0$ \\
\hline TAG $(\mathrm{mmol} / \mathrm{l})(\%)$ & $-5^{\star}$ & $-9,-1$ & $-5^{\star}$ & $-9,0$ & -4 & $-8,0$ \\
\hline \multicolumn{7}{|l|}{ Glycaemic biomarkers ( $n$ 218) } \\
\hline Glucose $(\mathrm{mmol} / \mathrm{l})(\%)$ & 0 & $-1,1$ & 0 & $-1,1$ & 0 & $-1,1$ \\
\hline $\mathrm{HbA}_{1 \mathrm{c}}(\%)$ & 0.02 & $-0.03,0.06$ & 0.02 & $-0.02,0.06$ & 0.02 & $-0.03,0.05$ \\
\hline Men & $-0.09^{\star \star *}$ & $-0.13,-0.04$ & $-0.09^{* * *}$ & $-0.14,-0.04$ & $-0.07^{\star *}$ & $-0.12,-0.02$ \\
\hline Women & 0.02 & $-0.03,0.06$ & 0.02 & $-0.02,0.06$ & 0.02 & $-0.02,0.05$ \\
\hline Insulin (pmol/l) (\%) & -4 & $-10,2$ & -2 & $-7,5$ & -3 & $-8,3$ \\
\hline Men (\%) & $-12^{\star \star *}$ & $-19,-6$ & $-13^{\star \star \star}$ & $-19,-7$ & $-9^{* *}$ & $-15,-3$ \\
\hline Women (\%) & -4 & $-10,2$ & -7 & $-7,5$ & -3 & $-8,3$ \\
\hline HOMA-IR (\%) & -4 & $-10,3$ & -1 & $-7,6$ & -2 & $-8,4$ \\
\hline Men (\%) & $-13^{\star \star \star}$ & $-20,-6$ & $-14^{\star \star \star}$ & $-21,-7$ & $-10^{\star \star}$ & $-16,-3$ \\
\hline Women (\%) & -4 & $-10,3$ & -1 & $-7,6$ & -2 & $-8,4$ \\
\hline
\end{tabular}

BP, blood pressure; hsCRP, high-sensitivity C-reactive protein; HOMA-IR, homoeostatic model of insulin resistance.

${ }^{\star} P<0.05,{ }^{* *} P \leq 0.01,{ }^{* \star *} P=0.001$.

$\dagger$ Simple linear regression model adjusted for sex and age.

$\ddagger$ Multiple linear regression analysis adjusted for sex, age, education, physical activity at leisure time.

$\S$ Multiple linear regression analysis adjusted for sex, age, education, physical activity at leisure time and BMI.

$\| n$ 216, after exclusion of those using BP-lowering medication.

If $n 204$ due to lack in biochemical analyses of hsCRP.

the sex-specific association between DQI and systolic BP and DQI and hsCRP was no longer present when we controlled for the effect of BMI. Here a positive association between DQI and Systolic BP and an inverse association between DQI and hsCRP were seen for the whole study population. Additionally, in the sensitivity analysis excluding UR and OR, a non-sex-specific significant association between DQI and trunk fat, systolic BP and hsCRP was observed. These results suggest that the observed sex-specific associations between DQI and the metabolic biomarkers BMI, trunk fat, systolic BP and hsCRP found in the analysis, including UR and OR, could be explained by dietary report errors. However, the results of the sensitivity analysis should be interpreted with caution, because of potential power issues when removing UR and OR from the analysis.

The inverse relationship between BMI and CRP is well recognised, and, moreover, it has been recognised that with increased adiposity CRP is further elevated ${ }^{(34)}$. The link between these risk factors is supported by the results of the present study, where an inverse association between DQI and BMI, trunk fat and hsCRP was found in men.

In addition, when controlling for the effect of BMI, the observed positive association between DQI and HDLcholesterol was only significant in study participants aged 50 years or above, suggesting that BMI is a more important mediator for HDL-cholesterol levels for people less than 50 years of age. However, genetic studies have lately challenged the common concept of raising HDL-cholesterol as a marker for CVD risk reduction, and further studies are need to investigate the role of HDL-cholesterol in CVD prevention ${ }^{(35,36)}$.

A main advantage of this study is the detailed assessment of the dietary data with the habitual diet measured during a 7-d consecutive dietary record using a validated method used for 
the past two decades in the Danish National Survey of Dietary Habits and Physical Activity ${ }^{(21,37)}$. In addition, this study uses a DQI based on five food and nutrients from the Danish FBDG relevant for IHD risk, and thus a relatively easy way to measure adherence to the overall current FBDG. A limitation of this study is the observational design of the cross-sectional study, as this design does not allow conclusions on cause and effect relationships. Therefore, extrapolation of the results should only be made with caution as the study participants resided in areas of Greater Copenhagen with a relatively higher level of education compared with the general Danish population ${ }^{(37)}$.

The sex-specific results with an inverse association in men only between DQI and the cardiometabolic risk factors BMI, trunk fat, hsCRP, $\mathrm{HbA}_{1 \mathrm{c}}$, insulin and HOMA-IR are in line with two cohort studies using the $\mathrm{HEI}^{(38,39)}$. The cross-sectional study by Drewnowski et al. ${ }^{(39)}$ including 5081 men and women, middle-aged French citizens with low CVD risk, investigated the association between the HEI and cardiovascular risk factors. Here an inverse association between the HEI and BMI was found in men only. Furthermore, Frazier-Woods et al. observed in another cross-sectional study containing 9797 adults men and women, with at least one CVD risk factor, that in men only the HEI score was inversely associated with insulin, HOMA-IR, HDL-cholesterol, TAG and $\mathrm{CRP}^{(38)}$. In contrast to our results, when Frazier-Wood et al. adjusted for BMI, the results were no longer significant. This strengthens the importance of BMI as an important factor in CVD prevention ${ }^{(38)}$

The sex-specific differences in the results in the present study could be accounted for by alcohol intake of those of the study participants who drank alcohol ( $n$ 194), as the men in the study drank more alcohol than the women. The median alcohol intake of the women was $3.9 \mathrm{E} \%$, whereas the men had a median alcohol intake of $6.5 \mathrm{E} \%$. It could be that men with a higher adherence to the Danish FBDG, expressed by a higher DQI score, also had a lower alcohol intake equivalent to the Danish recommendations of max seven drinks per week, corresponding to approximately $1 \mathrm{drink} / \mathrm{d}$. A recent meta-analysis of 84 prospective cohort studies found that alcohol consumption of $2 \cdot 5-14.9 \mathrm{~g} / \mathrm{d}$ (about $\leq 1 \mathrm{drink} / \mathrm{d}$ ) was associated with a lower risk of cardiovascular mortality, compared with abstaining from alcohol ${ }^{(40)}$. This is supported by the findings of the present study, where we found that a higher DQI score was associated with a more beneficial cardiometabolic risk profile.

One other cross-sectional study by Toft et al. investigated the association between adherence to Danish FBDG, assessed by a DQS and CVD risk factors ${ }^{(19)}$. In this cross-sectional study including 6542 healthy men and women aged 30-60 years, it was found, in line with the findings of the present study, that higher adherence to the Danish FBDG 2005 was associated with a more beneficial CVD risk factor profile. In agreement with our results, Toft et al. also found that the DQS was inversely associated with TAG, but in contrast to our results the DQS was inversely associated with total cholesterol and LDL-cholesterol. However, Toft et al. did not find a positive association between the DQS and HDL-cholesterol like in the present study.

Furthermore, our results are supported by the findings of another cross-sectional study by Babio et al. investigating adherence to a traditional Mediterranean diet (using a 14-point score) and risk of metabolic syndrome, which is a cluster of common CVD risk factors, including central obesity, hyperglycaemia, low HDL-cholesterol levels, hypertension and hypertriglyceridaemia $^{(41)}$. The traditional Mediterranean diet investigated by Babio et al. is characterised by a food pattern high in fruit, vegetables, grains and unsaturated fat and low in saturated fats ${ }^{(42)}$. This food pattern is comparable with the five food and nutrient indicators of the DQI used in this present study to investigate adherence to the Danish FBDG. Babio et al. found that a higher adherence to a traditional Mediterranean diet was associated with lower odds of having metabolic syndrome. In addition, Babio et al. found that subjects in the fourth quartile of the Mediterranean diet adherence, when compared with subjects in the lowest quartile of adherence to the Mediterranean diet, had 47 and 54\% lower odds of having low HDL-cholesterol levels and high TAG levels, respectively. However, in contrast to the low-risk middle-aged study participants of the present study, Babio et al. included 808 elderly high cardiovascular risk participants of the Reus PREDIMED Centre.

$\mathrm{BP}$ is known to be a variable measurement, and it can be hard to measure accurately. The surprising and unexpected finding of a positive association between the DQI and systolic BP is not in line with previous studies. In a meta-analysis of seventeen randomised controlled trials investigating the effect of dietary patterns on BP in adults, it was found that healthy dietary patterns such as the Nordic diet, the Mediterranean diet and the Dietary Approaches to Stop Hypertension decreased systolic and diastolic $\mathrm{BP}^{(43)}$.

When comparing the results of the previously mentioned studies and the results of the present study, it is important to be aware of differences between first and foremost the study populations, as some were middle-aged with low CVD risk ${ }^{(39)}$, and some older with features of the metabolic syndrome and therefore were at high CVD risk ${ }^{(41)}$, all of which can have an effect on the results on cardiometabolic risk factors. Moreover, awareness of the different methods of dietary assessment is important, as it could play a role for the accuracy of estimating dietary intake $e^{(19,38,39,41)}$. Furthermore, the DQI used in the present study include various factors of more or less importance for cardiometabolic risk factors. In particular, the score of whole-grain intake included in the DQI is of importance, as a high whole-grain intake is associated with lower risk of $\mathrm{CVD}^{(44)}$. In addition, looking at the individual scores of the five food and nutrients included in the DQI, the median score for added sugar was higher than the other median individual scores for whole grains, fish, fruit and vegetables and saturated fat, indicating a higher compliance to this specific dietary guideline of a reduced sugar intake.

Using a dietary index approach enabled us to describe associations between food and nutrient intake in individuals with dietary patterns more or less compliant with the current Danish FBDG and cardiometabolic risk factors. Overall, the present cross-sectional study adds to the growing body of evidence that adherence to different national FBDG and diets rich in fruit, vegetables, whole grains, legumes and fish and low in meat and sweets are associated with a better cardiometabolic risk profile. 
In conclusion, higher adherence to the current Danish FBDG, assessed by a DQI comprising of five components, was associated with a more beneficial cardiometabolic risk profile in a Danish adult population with a minimum of one self-rated risk factor for IHD. The DQI was inversely associated with BMI, trunk fat, hsCRP and glycaemic biomarkers in men.

The results substantiate the use of the DQI to measure adherence to the current Danish FBDG and associations with cardiometabolic risk factors, and indicate that adherence to the Danish FBDG may be beneficial for prevention of CVD. The results of this study further highlight the need to conduct sexstratified analyses on CVD risk in this particular target group.

\section{Acknowledgements}

The authors would like to thank research assistant Lise Schiff, research assistant Mia Smedmann Lausten and project coordinator Majken Ege for assisting with study materials, coordination and data collection, and senior adviser Tue Christensen for processing the dietary data. Also a special thanks to the staff at the study site at Gentofte Hospital, Denmark, for good collaboration during the data collection periods. Last but not least the authors would like to thank all the study participants for participating in the DIPI randomised controlled trial.

This work is part of the project Diet and Prevention of Ischemic Heart Disease - a Translational Approach study (DIPI), which is supported by the Danish Council for Strategic Research (contract 0603-00488B). The Danish Council for Strategic Research had no role in the design, analysis or writing of this article.

The author contributions are as follows: J. L. A., K. O. and I. T. formulated the research question; J. L. A., C. H. and I. T. contributed to the study design; J. L. A. performed the statistical analyses; J. L. A., C. H., E. W. A., K. O. and I. T. were all involved in the interpretation of the data and critical revision of the manuscript; J. L. A. drafted the manuscript and all authors approved the final version.

None of the authors has any conflicts of interest to declare.

\section{Supplementary material}

For supplementary material/s referred to in this article, please visit https://doi.org/10.1017/S0007114517003695

\section{References}

1. World Health Organization (2014) Global Status Report on Noncommunicable Diseases 2014; Attaining the Nine Global Noncommunicable Diseases Targets; a Shared Responsibility. Geneva, Geneva: WHO.

2. World Health Organization (2003) Diet, Nutrition and the Prevention of Chronic Diseases. WHO Technical Report Series, no. 916]. Geneva: WHO.

3. Van Horn L, McCoin M, Kris-Etherton PM, et al. (2008) The evidence for dietary prevention and treatment of cardiovascular disease. J Am Diet Assoc 108, 287-331.

4. World Health Organization (2015) Health in 2015: from MDGs, Millennium Development Goals to SDGs, Sustainable Development Goals. Geneva: WHO.
5. Ocké MC (2013) Evaluation of methodologies for assessing the overall diet: dietary quality scores and dietary pattern analysis. Proc Nutr Soc 72, 191-199.

6. Hu FB (2002) Dietary pattern analysis: a new direction in nutritional epidemiology. Curr Opin Lipidol 13, 3-9.

7. Hlebowicz J, Drake I, Gullberg B, et al. (2013) A high diet quality is associated with lower incidence of cardiovascular events in the Malmö diet and cancer cohort. PLOS ONE 8, e71095.

8. Nordic Council of Ministers (2014) Nordic Nutrition Recommendations 2012. Integrating Nutrition and Physical Activity, 5th ed. Copenhagen: Nordic Council of Ministers.

9. Schwingshackl L \& Hoffmann G (2015) Diet quality as assessed by the Healthy Eating Index, the Alternate Healthy Eating Index, the Dietary Approaches to Stop Hypertension score, and health outcomes: a systematic review and meta-analysis of cohort studies. J Acad Nutr Diet 115, 780-800.e5.

10. Waijers PMCM, Feskens EJM \& Ocké MC (2007) A critical review of predefined diet quality scores. Br J Nutr $\mathbf{9 7}$, 219-231.

11. Guenther PM, Casavale KO, Reedy J, et al. (2013) Update of the Healthy Eating Index: HEI-2010. J Acad Nutr Diet 113, 569-580.

12. Sofi F, Macchi C, Abbate R, et al. (2013) Mediterranean diet and health status: an updated meta-analysis and a proposal for a literature-based adherence score. Public Health Nutr 17, $2769-2782$

13. Grosso G, Marventano S, Yang J, et al. (2017) A comprehensive meta-analysis on evidence of Mediterranean diet and cardiovascular disease: are individual components equal? Crit Rev Food Sci Nutr 57, 3218-3232.

14. Alkerwi A, Vernier C, Crichton GE, et al. (2014) Cross-comparison of diet quality indices for predicting chronic disease risk: findings from the Observation of Cardiovascular Risk Factors in Luxembourg (ORISCAV-LUX) study. Br J Nutr 113, $1-11$.

15. Esposito K, Maiorino MI, Bellastella G, et al. (2015) A journey into a Mediterranean diet and type 2 diabetes: a systematic review with meta-analyses. BMJ Open 5, e008222.

16. Onvani S, Haghighatdoost F, Surkan PJ, et al. (2017) Adherence to the Healthy Eating Index and Alternative Healthy Eating Index dietary patterns and mortality from all causes, cardiovascular disease and cancer: a meta- analysis of observational studies. J Hum Nutr Diet 30, 216-226.

17. Mithril C, Dragsted LO, Meyer C, et al. (2013) Dietary composition and nutrient content of the New Nordic Diet. Public Health Nutr 16, 777-785.

18. Tetens I, Andersen LB, Astrup A, et al. (2013) Evidensgrundlaget for danske råd om kost og fysisk aktivitet (The Evidence-Base for the Danish Guidelines for Diet and Physical Activity). Søborg: National Food Institute, Technical University of Denmark.

19. Toft U, Kristoffersen L, Lau C, et al. (2007) The Dietary Quality Score: validation and association with cardiovascular risk factors: the Inter99 study. Eur J Clin Nutr 61, 270-278.

20. Knudsen VK, Fagt S, Trolle E, et al. (2012) Evaluation of dietary intake in Danish adults by means of an index based on food-based dietary guidelines. Food Nutr Res 2012, 56.

21. Biltoft-Jensen A, Matthiessen J, Rasmussen LB, et al. (2009) Validation of the Danish 7-day pre-coded food diary among adults: energy intake $v$. energy expenditure and recording length. Br J Nutr 102, 1838-1846.

22. Sørensen MR, Matthiessen J, Holm L, et al. (2017) Optimistic and pessimistic self-assessment of own diets is associated with age, self-rated health and weight status in Danish adults. Appetite 114, 15-22. 
23. Pedersen CB (2011) The Danish Civil Registration System. Scand J Public Health 39, 22-25.

24. Biltoft-Jensen A, Bysted A, Trolle E, et al. (2013) Evaluation of Web-based Dietary Assessment Software for Children: comparing reported fruit, juice and vegetable intakes with plasma carotenoid concentration and school lunch observations. Br J Nutr 110, 186-195.

25. Biltoft-Jensen A, Trolle E, Christensen T, et al. (2014) WebDASC: a web-based dietary assessment software for 8-11year-old Danish children. J Hum Nutr Diet 27, Suppl. 1, 43-53.

26. Black AE (2000) Critical evaluation of energy intake using the Goldberg cut-off for energy intake:basal metabolic rate. A practical guide to its calculation, use and limitations. Int J Obes Relat Metab Disord 24, 1119-1130.

27. Goldberg GR, Black AE, Jebb SA, et al. (1991) Critical evaluation of energy intake data using fundamental principles of energy physiology: 1 . Derivation of cut-off limits to identify under-recording. Eur J Clin Nutr 45, 569-581.

28. Friedewald WT, Levy RI \& Fredrickson DS (1972) Estimation of the concentration of low-density lipoprotein cholesterol in plasma, without use of the preparative ultracentrifuge. Clin Chem 18, 499-502.

29. Matthews DR, Hosker JP, Rudenski AS, et al. (1985) Homeostasis model assessment: insulin resistance and beta-cell function from fasting plasma glucose and insulin concentrations in man. Diabetologia 28, 412-419.

30. Sundhedsstyrelsen (2014) Danskernes Sundhed - Den Nationale Sundhedsprofil 2013 (Danes Health - National Health Profile 2013). Copenhagen: Sundhedsstyrelsen.

31. Estruch R, Martínez-González MA, Corella D, et al. (2006) Effects of a Mediterranean-Style diet on cardiovascular risk factors. Ann Intern Med 145, 1.

32. McCarron DA \& Reusser ME (2000) The power of food to improve multiple cardiovascular risk factors. Curr Atheroscler Rep 2, 482-486.

33. Goff LM, Cowland DE, Hooper L, et al. (2013) Low glycaemic index diets and blood lipids: a systematic review and meta-analysis of randomised controlled trials. Nutr Metab Cardiovasc Dis 23, 1-10.

34. Timpson N, Nordestgaard B, Harbord R, et al. (2010) Creactive protein levels and body mass index: elucidating direction of causation through reciprocal Mendelian randomization. Int J Obes 35, 300-308.

35. Zanoni P, Khetarpal SA, Larach DB, et al. (2016) Rare variant in scavenger receptor BI raises HDL cholesterol and increases risk of coronary heart disease. Science 351, 1166-1171.

36. Arsenault BJ \& Després J-P (2012) Lipids: HDL cholesterol is not HDL - don't judge the book by its cover. Nat Rev Cardiol 9, 557-558.

37. Pedersen AN, Christensen T, Matthiessen J, et al. (2015) Danskernes kostvaner 2011-2013. Hovedresultater (Dietary Habits in Denmark 2011-2013. Main Results). Søborg: National Food Institute, Technical University of Denmark.

38. Frazier-Wood AC, Kim J, Davis JS, et al. (2015) In crosssectional observations, dietary quality is not associated with CVD risk in women; in men the positive association is accounted for by BMI. Br J Nutr 113, 1244-1253.

39. Drewnowski A, Fiddler EC, Dauchet L, et al. (2009) Diet quality measures and cardiovascular risk factors in France: applying the Healthy Eating Index to the SU.VI.MAX Study JACN 28, 22-29.

40. Ronksley PE, Brien SE, Turner BJ, et al. (2011) Association of alcohol consumption with selected cardiovascular disease outcomes: a systematic review and meta-analysis. BMJ 342, d671-d671.

41. Babio N, Bulló M, Basora J, et al. (2009) Adherence to the Mediterranean diet and risk of metabolic syndrome and its components on behalf of the Nureta-PREDIMED investigators. Nutr Metab Cardiovasc Dis 19, 563-570.

42. Schwingshackl L, Schwedhelm C, Galbete C, et al. (2017) Adherence to Mediterranean diet and risk of cancer: an updated systematic review and meta-analysis. Nutrients 9 , 1063.

43. Ndanuko RN, Tapsell LC, Charlton KE, et al. (2016) Dietary patterns and blood pressure in adults: A systematic review and meta-analysis of randomized controlled trials. Adv Nutr An Int Rev J 7, 76-89.

44. Aune D, Keum N, Giovannucci E, et al. (2016) Whole grain consumption and risk of cardiovascular disease, cancer, and all cause and cause specific mortality: systematic review and dose-response meta-analysis of prospective studies. BMJ $\mathbf{3 5 3}$, i2716. 